\title{
A cytogenetic analysis in two cases of malignant peripheral nerve sheath tumor showing hypodiploid karyotype
}

\author{
MASAKO ISHIGURO ${ }^{1}$, HIROSHI IWASAKI ${ }^{1}$, MORISHIGE TAKESHITA $^{1}$, \\ YUMIKO HIROSE $^{2}$ and YASUHIKO KANEKO ${ }^{3}$ \\ ${ }^{1}$ Department of Pathology, ${ }^{2}$ Molecular Oncology Center, Fukuoka University, Fukuoka; \\ ${ }^{3}$ Laboratory Medicine, Saitama Cancer Center, Saitama, Japan
}

Received March 27, 2006; Accepted April 28, 2006

\begin{abstract}
In this study, we report cytogenetic findings in two cases of malignant peripheral nerve sheath tumor (MPNST) with hypodiploid karyotypes. A G-band technique, multicolor fluorescence in situ hybridization (m-FISH) and comparative genomic hybridization (CGH) were used and compared in this investigation. In both tumors, the G-band and m-FISH analysis demonstrated multiple rearrangements on chromosomes 1-5, 8-12, 15-17, 20 and 21, whereas CGH exhibited gains at 8q and $4 \mathrm{q}$. Both of the structural aberrations and the genomic imbalances of the chromosomes may play an important role in the pathogenesis and development of MPNST. No cytogenetic abnormalities specific for MPNST were found in the present cases or in other previously reported cases. This may reflect the diversity or heterogeneity of MPNST that exhibit various clinical and histological features. However, there are few cases described in detail on a morphologic pattern of MPNST, a correlation between the cytogenetic aberrations and the histologic patterns are still uncertain.
\end{abstract}

\section{Introduction}

Malignant peripheral nerve sheath tumor (MPNST) is a rare neoplasm arising from peripheral nerves and can occur sporadically or in association with neurofibromatosis 1 (NF1; von Recklinghausen's disease) (1). Although it clearly originates from peripheral nerves, MPNST is one of the most difficult diagnoses in pathology owing to its morphologic diversity. In only $50 \%$ of MPNST, immunohistochemical examination shows a positive reaction to the neural marker S-100 protein (2).

Cytogenetic analyses of MPNST have been reported in more than 100 cases. Their chromosome ploidy distributes

Correspondence to: Professor H. Iwasaki, Department of Pathology, Fukuoka University School of Medicine, 7-45-1 Nanakuma, Jonan-ku, Fukuoka 814-0180, Japan

E-mail: iwasaki@fukuoka-u.ac.jp

Key words: malignant peripheral nerve sheath tumor, neurofibromatosis, sarcoma, $\mathrm{CGH}, \mathrm{mFISH}$, karyotype, chromosome between hypodiploid and tetraploid, some tumors have been described as hypodiploid (3-8). Regardless of ploidy range, however, karyotypes of MPNST exhibit complex abnormalities with numerical and structural changes (3-13). Cytogenetic aberrations on chromosomes 1, 2, 5, 7-9, 11-14, 17, 18 and 22 were found to be the most frequent, although no consistent karyotypic patterns have been detected (3-18).

In the present study, we examined the cytogenetic details of two tumors of myxoid MPNST with hypodiploid karyotypes by combining conventional G-band, multicolor fluorescence in situ hybridization (m-FISH) and comparative genomic hybridization $(\mathrm{CGH})$ techniques, and compared the results with existing cytogenetic information of MPNST to consider its relevance to carcinogenesis.

\section{Materials and methods}

\section{Clinical data}

Case 1. A 46-year-old man noticed a painless mass on the left side of his neck. The mass was excised and diagnosed histologically as MPNST; the patient showed no clinical signs of neurofibromatosis. Three years later, a recurrent tumor developed at the same site and was surgically removed. One year later, the tumor recurred for a third time at the same site and was again excised. A sample was collected for cytogenetic analysis from the initial recurrent tumor.

Case 2. A 70-year-old man had low back pain for a period of 4 years. He felt pain in his left leg for one month and it became difficult to walk. A computer tomography (CT) evaluation revealed a tumor in his left buttock. The tumor was surgically removed and diagnosed as MPNST; no clinical signs of neurofibromatosis were present.

Cytogenetic analysis. We received tissue samples from the recurrent tumor in case 1 and from the primary gluteal tumor in case 2. Tumor tissues from each patient were disaggregated with collagenase, cultured and harvested as previously described (19). The trypsin-Giemsa banding technique was performed for the karyotypic analysis. The karyotype was expressed according to the detailed system of the International System for Human Cytogenetic Nomenclature (ISCN 1995) (20). A multicolor painting was employed with the 24XCyte mFISH probe kit according to the recommendations of the manufacturer (Meta systems $\mathrm{GmbH}$, Germany). Slides were 
Table I. Antibodies and immunohistochemical conditions.

\begin{tabular}{lllc}
\hline Antibodies & Dilution & \multicolumn{1}{c}{ Source } & Pretreatment \\
\hline Vimentin & $1: 100$ & Dako & + \\
S-100 & Prediluted & Nishirei, Japan & - \\
NSE & $1: 200$ & Dako & + \\
Leu7 (CD 57) & $1: 50$ & BK & + \\
CD34 (My10) & $1: 40$ & BK & + \\
EMA & $1: 100$ & Dako & + \\
CK AE1/AE3 & $1: 50$ & Dako & + \\
CK 7 & $1: 50$ & Dako & + \\
CAM5.2 & Prediluted & BK & + \\
CD56 & $1: 25$ & Dako & + \\
Desmin & $1: 100$ & Dako & + \\
HHF35 & $1: 50$ & Enzo, NY, USA & - \\
$\alpha-S M A$ & $1: 100$ & Dako & - \\
HMB45 & $1: 50$ & Dako & - \\
MyoD1 & $1: 100$ & Dako & - \\
p53 (DO7) & $1: 100$ & Novocastra, UK & + \\
\hline
\end{tabular}

EMA, epithelial membrane antigen; NSE, neuronspecfic enolase; Dako, Dakopatts, Denmark; BK, Becton-Dickinson.

observed with a Zeiss Axioplan 2 microscope (Carl Zeiss Jena $\mathrm{GmbH}$, Jena, Germany). Images were captured with a Sensys CCD camera and analyzed by using the automated mFISH analysis software (MetaSystems, Altlusheim, Germany) based on the digital image analysis system (Isis, Carl Zeiss Vision, Oberkochen, Germany).

Comparative genomic hybridization. DNA was extracted from fresh frozen tissues and labeled directly with fluorescein12-dUTP (Roche Diagnostics, Mannheim, Germany) by nick translation (Vysis, Downers Grove, IL). SpectrumRed (Vysis) was used as the reference DNA and the hybridization procedure was carried out as described by Koga et al (18). Three-color CGH signals (red for reference DNA, green for tumor DNA and blue for counterstaining) were captured using a Zeiss Axioplan 2 microscope (Carl Zeiss Jena $\mathrm{GmbH}$ ) and analyzed with Isis/CGH software (Metasystems, Altlussheim, Germany). At least 10 representative images were analyzed to detect increases and decreases of DNA sequence copy numbers on the chromosome. The chromosomal regions with a green/red ratio above 1.20 were considered to have gained DNA sequence copy numbers, whereas regions with a ratio below 0.80 were considered to have lost DNA copy numbers. These cut-off values were based on measurements from a series of normal mail/femail control. Heterochromatic, centromeric and telomeric regions, the short arm of the acrocentric chromosomes and $\mathrm{Y}$ chromosome were excluded from evaluation, because these are known to be areas in which hybridization is unreliable (21).

Pathologic evaluations. Formalin-fixed, paraffin-embedded tissue samples were used for light microscopicy studies.
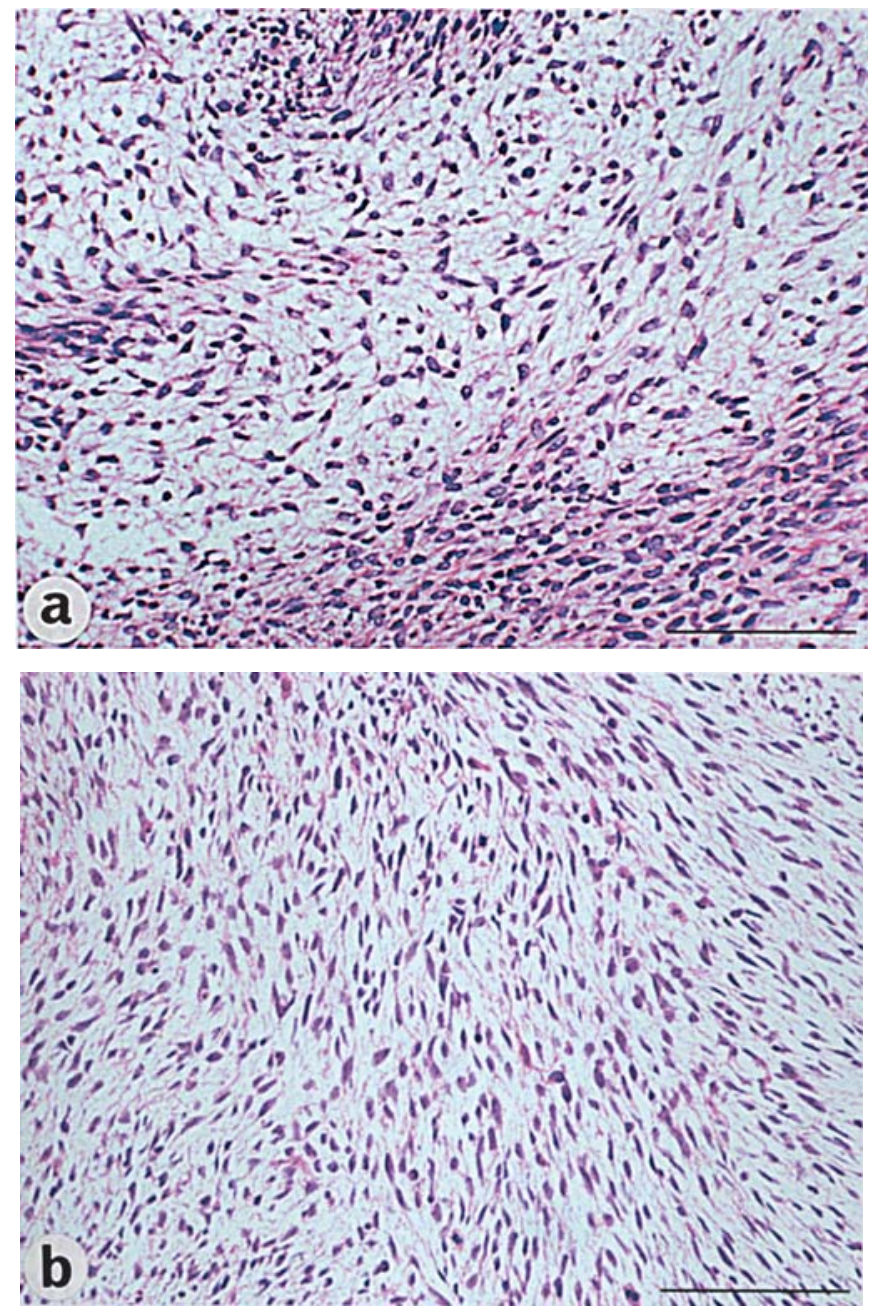

Figure 1. (a), The tumor is composed of a mixture of spindle cells, polyfonal cells and a few bizarre giant cells. A prominent myxoid feature is seen (H\&E). Scale bar, $100 \mu \mathrm{m}$. (b), Section shows spindle-shaped cells with wavy nuclei in a myxomatous background (H\&E). Scale bar, $100 \mu \mathrm{m}$.

Serial 3- $\mu \mathrm{m}$ thick sections were prepared on glass slides and stained with hematoxylin and eosin (H\&E). For immunocytochemistry of paraffin-embedded sections, antigen retrieval was performed for EMA, CytokeratinAE1/AE3, NSE, CD34, CD56, CD57, vimentin and p53 (clone DO-7) by using microwave pretreatment in standard citrate buffer $(0.01 \mathrm{M}, \mathrm{pH}$ 6.0). The summary of immunohistochemical conditions is listed in Table I. The samples were reacted with each of the primary antibodies for $1 \mathrm{~h}$ at room temperature. The bound antibodies were visualized using a labeled streptavidin-biotin system and an alkaline phosphatase technique.

\section{Results}

Pathologic findings. In case 1, the tumor showed a mixed proliferation of atypical spindle cells and round or stellate cells in a delicate fibrillar matrix. The tumor exhibited wide myxoid areas alternating with dense hypercellular foci and increased perivascular cellularity (Fig. 1a). Mitotic figures including abnormal forms were found among the tumor cells.

In case 2 , the tumor showed proliferation of spindleshaped cells with plump or wavy nuclei and fine, eosinophillic cytoplasm in a prominent myxomatous background (Fig. 1b). 


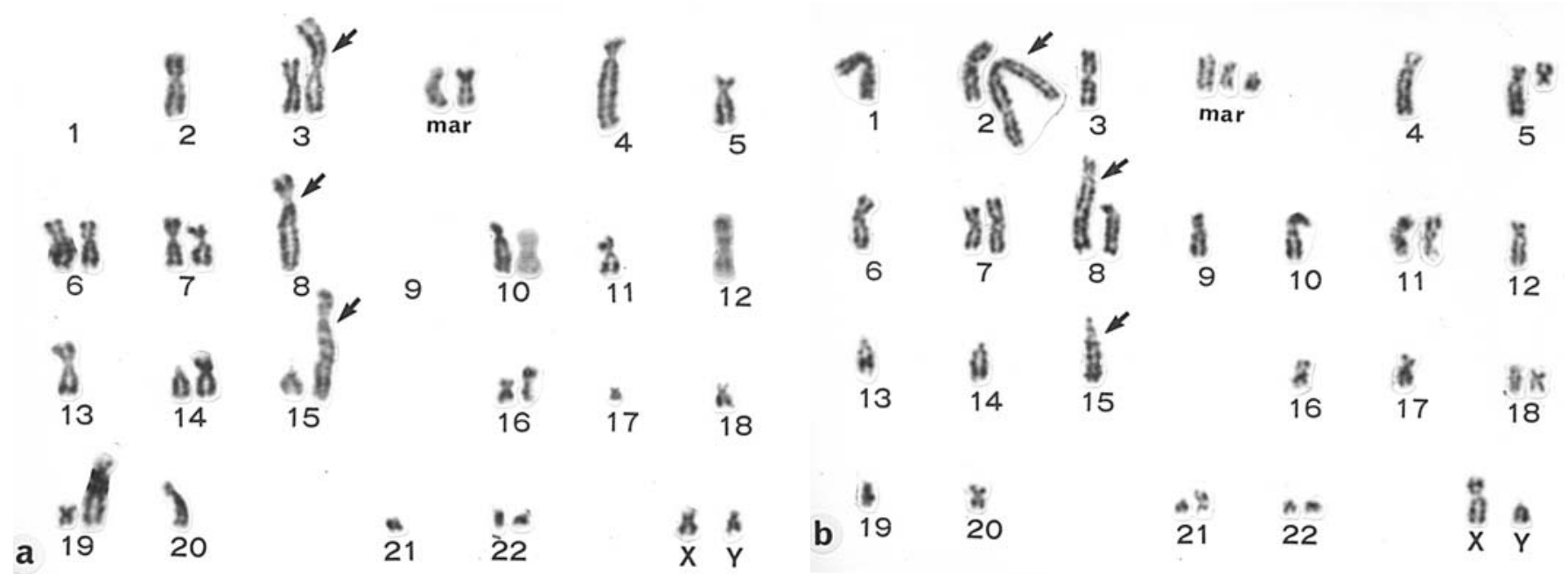

Figure 2. Representative G-banded karyotype revealed by m-FISH analysis [(a), case 1; (b), case 2]. Arrows point to unclassified marker chromosomes detected by G-band analysis alone.

Table II. Cytogenetic findings in two MPNST.

Case 1

Case 2

\begin{abstract}
$34, \mathrm{Y}, \operatorname{der}(\mathrm{X})(: \mathrm{p} 21 \rightarrow \mathrm{q} 22:),-1,-2, \operatorname{der}(3)(17 ? \rightarrow 17 ?:: 3 \mathrm{p} 11 \rightarrow 3 \mathrm{qter}),-4, \operatorname{der}(4)(4 \mathrm{pter} \rightarrow 4 \mathrm{q} 35:: 22 ? \rightarrow 22 ?:: 8 ? \rightarrow$ 8 ?), $, 5,-8, \operatorname{der}(8)(8 \mathrm{qter} \rightarrow 8 \mathrm{q} 10:: 8 \mathrm{q} 10 \rightarrow 8 \mathrm{qter}:: 9 ? \rightarrow 9 ?:: 3 ? \rightarrow 3 ?:: 19 ? \rightarrow 19 ?),-9,-9[3]$, der(10)(10pter $\rightarrow 10 \mathrm{q} 26$ $:: X q 23 \rightarrow$ Xqter $),-11,-12[4], \operatorname{der}(12)(4 ? \rightarrow 4 ?:: 12$ p13 $\rightarrow 12$ qter $),-13, \operatorname{der}(13)(3 ? \rightarrow 3 ?:: 13$ p11 $\rightarrow 13 q$ ter $), \operatorname{der}(14)$ $(4 ? \rightarrow 4 ?:: 22 ? \rightarrow 22 ?:: 14 q 10 \rightarrow 14 q$ ter $),-15, \operatorname{der}(15)(X ? \rightarrow X ?:: 12 ? \rightarrow 12 ?:: X ? \rightarrow X ?:: 20 ? \rightarrow 20 ?:: 15 p 10 \rightarrow 15$ qter::21? $\rightarrow 21 ?:: 9 ? \rightarrow 9 ?:: 1 \mathrm{q} 32 \rightarrow 1$ qter $), \operatorname{der}(16)(11 \mathrm{qter} \rightarrow 11 \mathrm{q} 10:: 16 \mathrm{p} 11 \rightarrow 16 \mathrm{qter}), \operatorname{der}(17)(: \mathrm{p} 12 \rightarrow \mathrm{q} 21:)$ $\operatorname{der}(19)(19$ pter $\rightarrow 19 q 13:: 3 ? \rightarrow 3 ?:: 2 q 11 \rightarrow 2 q$ ter $),-20, \operatorname{der}(20)(20$ pter $\rightarrow 20 q 12:: 8 q 12 \rightarrow 8 q$ ter $),-21,-22, \operatorname{der}(?)$ $(19 ? \rightarrow 19 ?:: 8 ? \rightarrow 8 ?:: 22 ? \rightarrow 22 ?:: 10 q 10 \rightarrow 10$ qter $),+2 \operatorname{mar}[\text { cp6 }]^{\mathrm{a}}$
\end{abstract}

a 8 cells showed normal karyotype.

Moderate nuclear atypia, scattered mitotic figures and focal necrosis were observed.

In both cases the tumor cells showed positive reactions for NSE, CD56 and vimentin. S-100 protein and CD57 were also positive in some cells. The tumor cells were uniformly negative for cytokeratin7, cytokeratin AE1/AE3, CAM5.2, HMB45, MyoD1, HHF35, desmin, EMA and CD34. Positive immunoreactions for $\mathrm{p} 53$ were observed in more than $60 \%$ of the tumor cell nuclei in case 1 and more than $10 \%$ of the tumor cell nuclei in case 2 .

Cytogenetic analysis. In case 1, 26 days of culture produced adequate metaphases whereas cultures sustained for 2, 12 and 23 days produced no metaphases. Twenty-three metaphases were analyzed and the modal chromosomal number was 34 . The karyotype based on G-band (Fig. 2a) in combination with
mFISH (Fig. 3a) showed hypodiploidy with complex abnormalities (Table II).

In case 2, 18 adequate metaphases were obtained at 53 days of culture and the cells passaged twice during cultivation. Forty-five metaphases were analyzed and the modal chromosomal number was 34 . The karyotype based on G-band (Fig. 2b) in combination with mFISH (Fig. 3b) showed hypodiploidy with complex abnormalities (Table II).

Comparative genomic hybridization. In case 1, the gains of DNA sequences were observed for $4 q 28 \rightarrow$ qter, $8 \mathrm{q}, 17 \mathrm{q} 22 \rightarrow$ qter and the losses of DNA sequences were observed for 4p14 $\rightarrow$ pter (Fig. 4a).

In case 2 the gains of DNA sequences were observed for $1 \mathrm{q} 21.3 \rightarrow \mathrm{q} 24,2 \mathrm{p} 22 \rightarrow$ pter, $2 \mathrm{q} 12 \rightarrow \mathrm{q} 14,2 \mathrm{q} 24 \rightarrow \mathrm{q} 32,4 \mathrm{p} 14 \rightarrow$ pter, $4 \mathrm{q} 26 \rightarrow$ qter, 5 p14 $\rightarrow$ p15.2, 5 q32 $\rightarrow$ qter, 7 p13 $\rightarrow$ pter, $8 \mathrm{q} 12 \rightarrow \mathrm{q} 21.1$, 

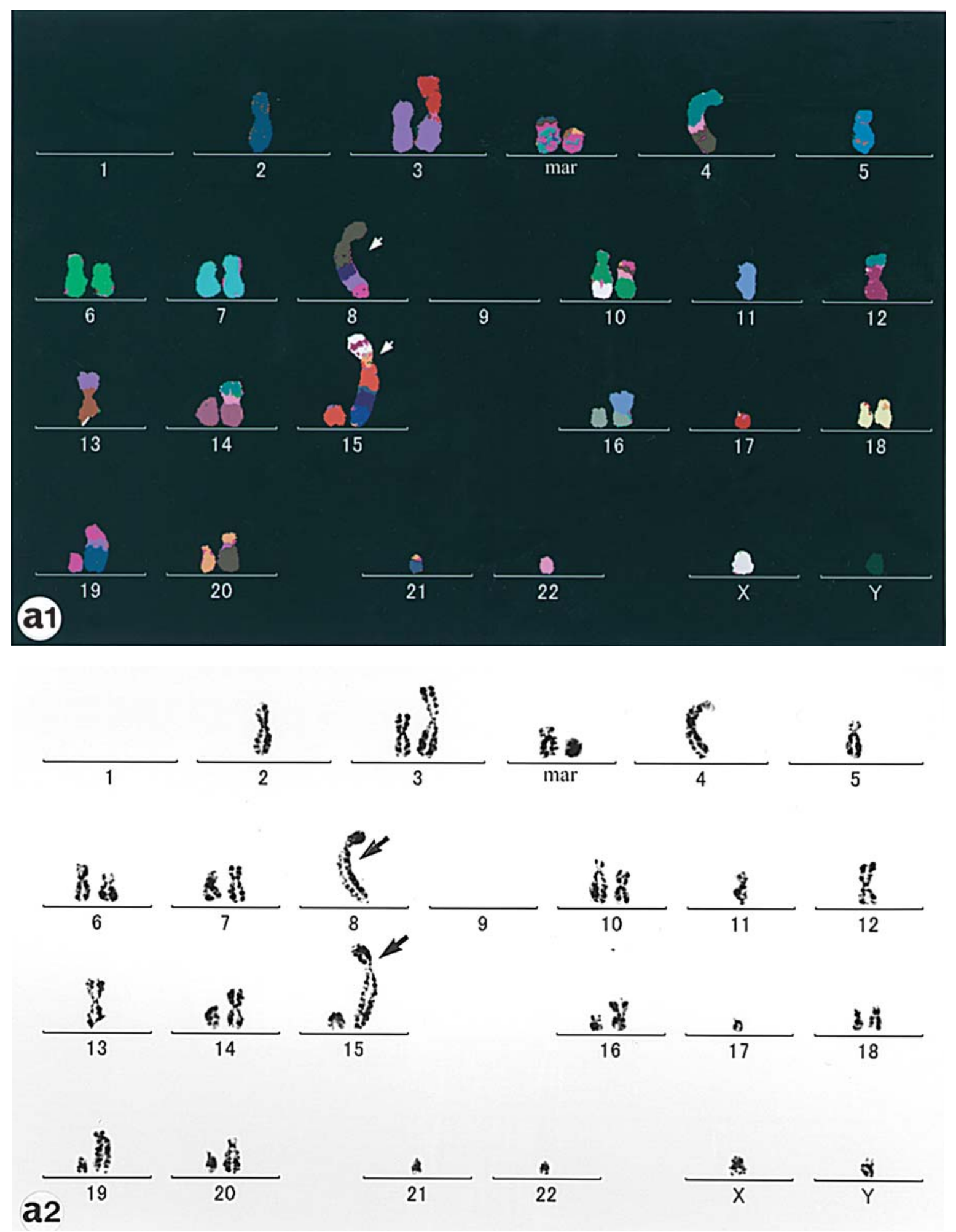

$12 \mathrm{q} 13 \rightarrow \mathrm{q} 21,15 \mathrm{q} 14 \rightarrow \mathrm{q} 24,21 \mathrm{q} 11.1 \rightarrow \mathrm{q} 22.1$; no DNA sequence losses were observed in case 2 (Fig. $4 b$ ).

\section{Discussion}

Histologically, malignant peripheral nerve sheath tumor (MPNST) is composed chiefly of spindle-shaped cells mixed with round or stellate cells. A differential diagnosis of malignancy therefore includes various spindle cell malignancies such as monophasic fibrous synovial sarcoma, fibrosarcoma, leiomyosarcoma, hemangiopericytoma and clear cell sarcoma (1). Both cases lacked signs of neurofibrmatosis 1 (NF1) and it was difficult to make a precise diagnosis based solely on histological findings; we therefore carried out immunohistochemical staining of the tumors to establish the diagnosis. The tumor cells showed positive immunoreactivities for vimentin and neural makers including NSE, S-100 protein, CD56 and CD57 and they were uniformly negative for myogenic, epithelial and melanocytic markers. On the basis of these results, the diagnosis of MPNST was established in both cases. 

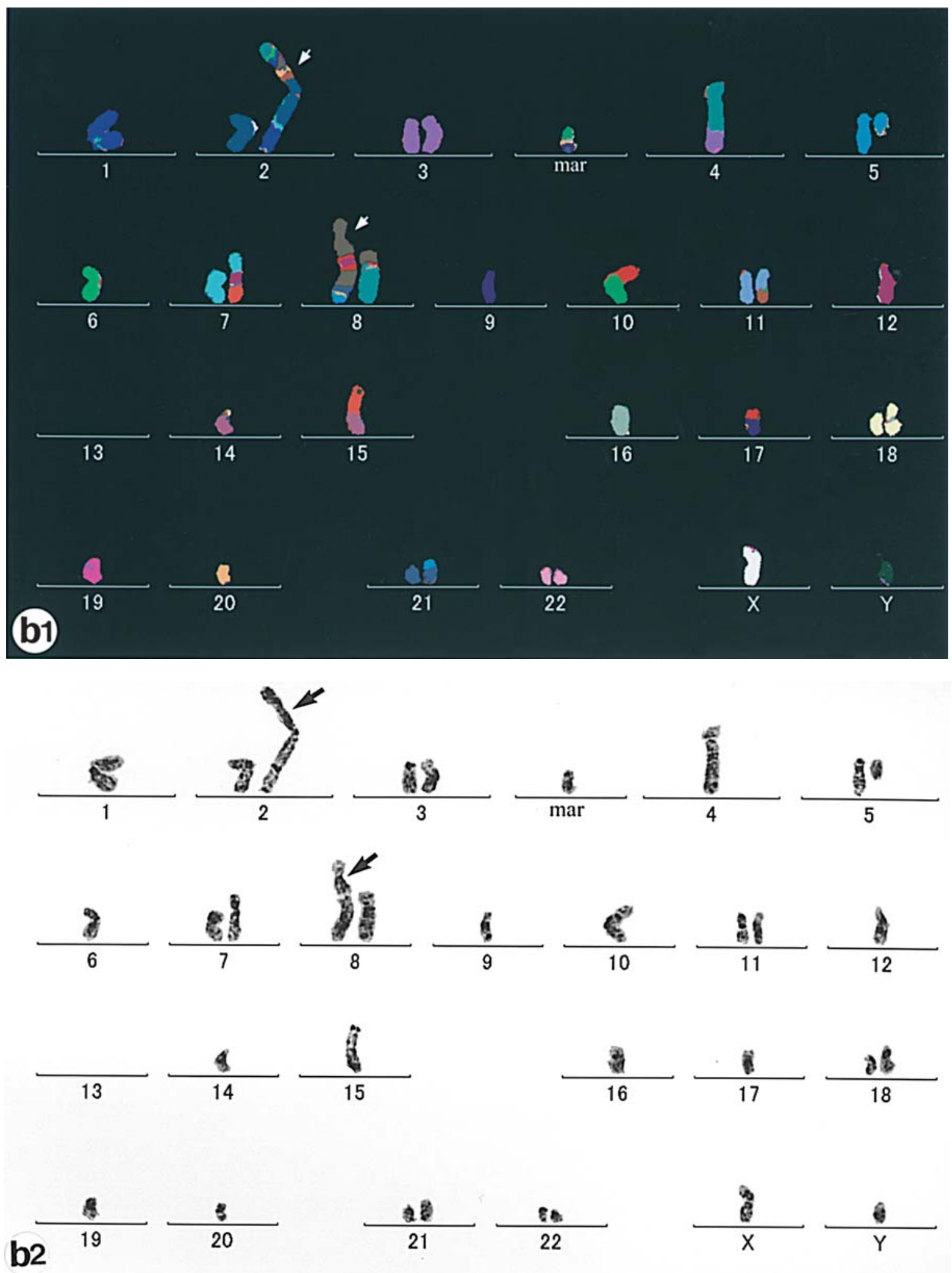

Figure 3. Complete m-FISH karyotypes in pseudo colors [(a1), case 1; (b1), case 2], and reverse DAPI banding pattern form the metaphase [(a2), case 1; (b2), case 2]. Some unclassified marker chromosomes detected by G-banding are composed of various portions of the affected chromosomes (arrows).

In recent years, many cytogenetic analyses of MPNST have been carried out utilizing the conventional G-band procedure and comparative genomic hybridization (CGH). As a result of these efforts, more than 100 cases of cytogenetic studies in which approximately 80 cases of chromosomal aberrations have been reported (3-18). The majority of them displayed highly complex karyotypes with many numerical and structural alterations. Their chromosome numbers varied with tetraploidy from hypodiploid range. Many chromosomal imbalances per sample were also detected by $\mathrm{CGH}$.

In the present cases, both tumors displayed the hypodiploid karyotype with complicated aberrations and some unclassified marker chromosomes. With the combination of G-band and m-FISH analyses, some unclassified marker 

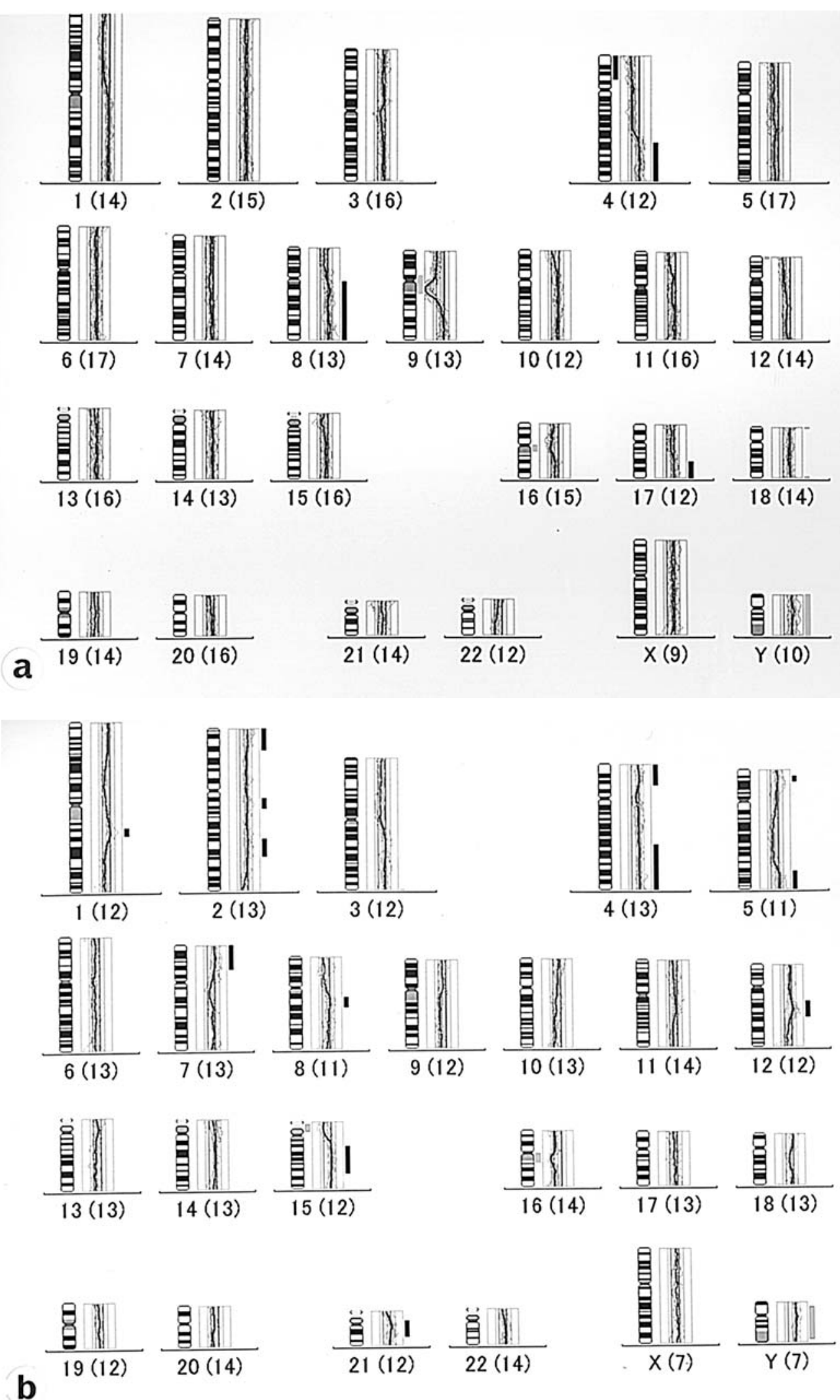

Figure 4. CGH single profiles of test to reference fluorescent intensity for each chromosome. Gains are shown on the right side of the profiles and the losses on the left by black bars [(a), case 1; (b), case 2]. Heterochromatic, centromeric and telomeric regions, the short arm of the acrocentric chromosomes and Y chromosome were excluded from the analysis and shown by the gray bars.

chromosomes could be identified (Fig. 2). A number of these chromosomes were proved to be composed of various portions of the affected chromosomes (Fig. 3). These results confirm the usefulness of m-FISH in the diagnosis of difficult cases of chromosomal aberration. As the structural aberrations were very complex and involved the frequent insertion or deletion of a single band, we were not able to determine even the chromosome number in some marker chromosomes. In a few 
instances, many rearrangements were distributed randomly throughout the entire length of the chromosome.

Recently published results highlight a recurrent pattern of chromosomal imbalance by $\mathrm{CGH}$. The recurrent gains of chromosome 1q, 5p, 6p, 7, 8q, 12, 13q, 15 and 17q the most frequent losses of chromosomes $1 p, 9 p, 11 p, 17 p$ and $17 q$ have been reported (3-18). Loss of chromosome $9 p$ is the most common feature in MPNST. CDNK2A has been mapped to $9 \mathrm{p} 21$ as a candidate tumor suppressor gene. The $C D N K 2 A$ encodes p16 and p14 ${ }^{\mathrm{ARF}}$ and inactivation of this gene impairs both RB1 and TP53 tumor suppressor pathways, respectively $(22,23)$. Tumor suppressor genes $p 53$ and NF1 are located on 17 p12 and 17q11.2, respectively. Functional inactivation of these genes may play an important role in MPNST progression and development $(9,24,25)$. Putative tumor suppressor genes located on chromosomes $1 \mathrm{p}$ and $11 \mathrm{q}$ are still unknown. In the present cases, we detected the gain of chromosome $17 \mathrm{q}$ by $\mathrm{CGH}$. Whereas we were unable to identify genomic imbalances using conventional banding analysis because of complicated aberrations of karyotype, however, structural aberration of chromosomes 1, 9, 11 and 17 were found. These chromosomal aberrations may cause disruption of the tumor suppressor genes and possibly inactivate their suppressor function. Immunohistochemical analysis detected overexpression of the $p 53$ gene product in both our tumors. The half-life of the wild-type $p 53$ gene product is much shorter than that of mutated $p 53$ gene products; this may explain the overexpression of $p 53$ immunoreactivity $(24,25)$.

$\mathrm{CGH}$ analysis of our tumors demonstrated that gains were more frequent than losses. This result supports the hypothesis that a proto-oncogene is predominant during tumor progression (16). In case $1, \mathrm{CGH}$ analysis demonstrated that the recurrent tumor had the gain of 17q22-qter. This agrees with a previous report that suggested that the gain of $17 \mathrm{q}$ is associated with poor clinical outcome in MPNST $(15,17)$. In case 2 , CGH analysis found gains on chromosomes 5p, 7, 8q, 12 and 15 . Gains in these chromosomes have been detected in several tumor types $(26,27)$.

In our two cases, the commonly affected chromosomes detected by G-band, m-FISH and CGH analysis were chromosomes 4 and 8. Gains of 4q28-qter and 8q12-21 were detected by $\mathrm{CGH}$ analysis. The gain in chromosome $4 \mathrm{q}$ detected by $\mathrm{CGH}$ analysis has been reported previously in peripheral nerve sheath tumors (18); however, the relationship between the aberration of $4 \mathrm{q}$ and pathogenesis in MPNST is not clarified. Although the gain in 8q occurs frequently in sporadic and NF1-associated MPNST, it also occurs in various kinds of malignant solid tumors $(10,12,17,26,27)$. The gain of $8 \mathrm{q}$ might therefore be associated with malignant tumor progression rather than the pathogenesis of MPNST.

These findings agree with a previous report that suggests MPNST develop by multi-step process with several genetic events (16). Several tumor suppressor genes and protooncogenes may contribute to tumorigenesis, development and progression in MPNST. This may explain the fact that in spite of many reports of numerical and structural cytogenetic aberrations in MPNST, an aberration common to all MPNST has not been found yet. Incidentally various combinations of genetic changes may reveal various histological patterns in MPNST. MPNST is one of the most difficult diagnoses in pathology due to the heterogeneity of their constituent cells and the morphologic diversity. However, there are not sufficient cases described in detail to suggest a correlation between phenotypic and genotypic features in MPNST. It is therefore necessary to investigate the possibility of a relationship between the histological patterns and the cytogenetic changes in a large series of MPNST.

\section{Acknowledgements}

The authors gratefully acknowledge the technical expertise of Ms. Chikako Fujita, Ms. Mutumi Yuki (Department of Pathology, Fukuoka University School of Medicine) and Ms. Hisayo Kanamaru (Fast Department of Surgery, Fukuoka University School of Medicine). This study was supported in part by funds from MEXT (15390119) and the Central Research Institute of Fukuoka University (041001).

\section{References}

1. Weiss SW and Goloblum JR: Enzinger and Weiss's soft tissue tumors. 4th edition. Mosby, St. Louis, pp1209-1241, 2001.

2. Daimaru Y, Hashimoto H and Enjoji M: Malignant peripheral nerve-sheath tumors (malignant schwannomas): an immunohistochemical study of 29 cases. Am J Surg Pathol 9: 434-444, 1985

3. Örndal C, Rydholm A, Willén H, Mitelman F and Mandahl N: Cytogenetic intratumor heterogeneity in soft tissue tumors. Cancer Genet Cytogenet 78: 127-137, 1994.

4. Mertens F, Rydholm A, Bauer HFC, Limon J, Nedoszytko B, Szadowska A, Willén H, Heim S, Mitelman F and Mandahl N: Cytogenetic findings in malignant peripheral nerve sheathe tumors. Int J Cancer 61: 793-798, 1995.

5. Rao UNM, Surti U, Hoffner J and Yaw K: Cytogenetic and histologic correlation peripheral nerve sheath tumors of soft tissue. Cancer Genet Cytogenet 88: 17-25, 1996.

6. Plaat BEC, Molenaar WM, Mastik MF, Hoekstra HJ, Te Meerman GJ and van den Berg E: Computer-assisted cytogenetic analysis of 51 malignant peripheral-nerve-sheath tumors: sporadic vs. neurofibromatosistype-1-associated malignant schwannomas. Int J Cancer 83: 171-178, 1999.

7. Mertens F, Dal Cin P, De Wever I, Fletcher CD, Mandahl N, Mitelman F, Rosai J, Rydholm A, Sciot R, Tallini G, van den Berghe H, Vanni R and Willen H: Cytogenetic characterization of peripheral nerve sheath tumors: a report of the CHAMP study group. J Pathol 190: 31-38, 2000.

8. Schmidt H, Taubert H, Wurl P, Bache M, Bartel F, Holzhausen HJ and Hinze R: Cytogenetic characterization of six malignant peripheral nerve sheath tumors: comparison of karyotyping and comparative genomic hybridization. Cancer Genet Cytogenet 128: 14-23, 2001.

9. Jhanwar SC, Chen Q, Li FP, Brnnan MF and Woodruff JM: Cytogenetic analysis of soft tissue sarcoma. Recurrent chromosome abnormalities in malignant peripheral nerve sheath tumors (MPNST). Cancer Genet Cytogenet 78: 138-144, 1994

10. McComb EN, McComb RD, De Boer JM, Neff JR and Bridge JA: Cytogenetic analysis of a malignant triton tumor and a malignant peripheral nerve sheath tumor and a review of the literature. Cancer Genet Cytogenet 91: 8-12, 1996.

11. Van Roy N, van Gele M, Vandesompele J, Messiaen L, van Belle S, Sciot R, Mortéle K, Gyselinck J, Michiels E, Forsyth R, van Marck E, De Paepe A and Speleman F: Evidence for involvement of a tumor suppressor gene on $1 \mathrm{p}$ in malignant peripheral nerve sheath tumors. Cancer Genet Cytogenet 143: 120-124, 2003.

12. Frank D, Gunawan B, Holtrup M and Fuzesi L: Cytogenetic characterization of three malignant peripheral nerve sheath tumors. Cancer Genet Cytogenet 144: 18-22, 2003.

13. Breidge RS Jr, Breidge JA, Neff JR, Naumann S, Althof P and Bruch LA: Recurrent chromosomal imbalances and structurally abnomal break-points within complex karyotypes of malignant peripheral nerve sheath tumor and malignant triton tumor: a cytogenetic and molecular cytogenetic study. J Clin Pathol 57: 1172-1178, 2004. 
14. Forus A, Weghuis DO, Smeets D, Fodstad $\varnothing$, Myklebost $O$ and van Kessel AG: Comparative genomic hybridization analysis of human sarcomas: I. Occurrence of genomic imbalances and identification of a novel major amplicon at 1q21-q22 in soft tissue sarcomas. Genes Chromosomes Cancer 14: 8-14, 1995.

15. Schmidt H, Würl P, Taubert H, Meye A, Bache M, Holzhausen HJ and Hinze R: Genomic imbalances of $7 p$ and $17 q$ in malignant peripheral nerve sheath tumors are clinically Rrelevant. Genes Chromosomes Cancer 25: 205-211, 1999.

16. Mechtersheimer G, Otaño-Joos M, Ohl S, Benner A, Lehnert T, Willeke F, Möller P, Otto HF, Lichter P and Joos S: Analysis of chromosomal imbalances in sporadic and NF1-associated peripheral nerve sheath tumors by comparative genomic hybridization. Genes Chromosomes Cancer 25: 362-369, 1999.

17. Schmidt H, Taubert H, Meye A, Würl P, Bache M, Bartel F, Holzhausen HJ and Hinze R: Gains in chromosomes 7, 8q, 15q and $17 \mathrm{q}$ are characteristic changes in malignant but not in benign peripheral nerve sheath tumors from patients with Recklinghausen's disease. Cancer Lett 155: 181-190, 2000.

18. Koga T, Iwasaki H, Ishiguro M, Matsuzaki A and Kikuchi M: Frequent genomic imbalances in chromosomes 17,19 and $22 \mathrm{q}$ in peripheral nerve sheath tumors detected by comparative genomic hybridization analysis. J Pathol 197: 98-107, 2002.

19. Ohjimi Y, Iwasaki H, Ishiguro M, Kaneko Y, Tashiro H, Emoto G, Ogata K and Kikuchi M: Short arm of chromosome 1 aberration recurrently found in pigmented villonodular synovitis. Cancer Genet Cytogenet 90: 80-85, 1996.

20. ISCN, An international system for human cytogenetic nomenclature. Mittelman F (ed). S. Karger, Basel, 1995.

21. Kallioniemi OP, Kallioniemi A, Piper J, Waldman FM, Gray JW and Pinkel D: Optimizing comparative genomic hybridization for analysis of DNA sequence copy number changes in solid tumors. Genes Chromosomes Cancer 10: 231-243, 1994.
22. Berner JM, Sørlie T, Mertens F, Henriksen J, Sæter G, Mandahl N, Brøgger A, Myklebost O and Lothe RA: Chromosme band 9p21 is frequently altered in malignant peripheral nerve sheath tumors: studies of CDKN2A and other gene of the pRB pathway. Genes Chromosomes Cancer 26: 151-160, 1999.

23. Kourea HP, Orlow I, Scheithauer BW, Cordon-Cardo C and Woodruff JM: Deletions of the INK4A gene occur in malignant peripheral nerve sheath tumors but not in neurofibromas. Am J Pathol 155: 1855-1860, 1999.

24. Halling KC, Scheithauer BW, Halling AC, Nascimento AG, Ziesmer SC Roche PC and Wollan PC: P53 expression in neurofibroma and malignant peripheral nerve sheath tumor. An immunohistochemical study of sporadic and NF1-associated tumors. Am J Clin Pathol 106: 282-288, 1996.

25. Mawrin C, Kirches E, Boltze C, Dietzmann K, Roessner A and Schneider-Stock R: Immunohistochemical and molecular analysis of p53, RB and PTEN in malignant peripheral nerve sheath tumors. Virchows Arch 440: 610-615, 2002.

26. Forozan F, Karhu R, Kononen J, Kallioniemi A and Kallioniemi O-P: Genome screening by comparative genomic hybridization. Trends Genet 13: 405-409, 1997.

27. Knuutila S, Björkqvist A-M, Autio K, Tarkkanen M, Wolf M, Monni O, Szumanska J, Larramendy ML, Tapper J, Pere H, EI-Rifai W, Hemmer S, Wasenius V-M, Vidgren V and Zhu Y: DNA copy number amplifications in human neoplasms. Review of comparative genomic hybridization studies. Am J Pathol 152: $1107-1123,1998$. 